\title{
Mononucleosis syndrome and coincidental human herpesvirus-7 and Epstein-Barr virus infection
}

\author{
H-H Chiu, C-Y Lee, P-I Lee, K-H Lin, L-M Huang
}

\begin{abstract}
Two girls (a 5 year old and a 21 month old) experiencing mononucleosis syndrome with coincidental human herpesvirus (HHV)-7 and Epstein-Barr virus (EBV) infections are described. One patient had primary $\mathrm{HHV}-7$ infection and reactivated EBV infection. The other had primary HHV-7 and EBV infections. These cases indicated that $\mathrm{HHV}-7$ is capable of inducing infectious mononucleosis-like illness. Multiple herpesvirus infection in one of the patients also suggests that interaction among herpesviruses can occur in vivo. The consequence of this interaction may have clinical implications.

(Arch Dis Child 1998;78:479-480)
\end{abstract}

Keywords: human herpesvirus; Epstein-Barr virus; mononucleosis

The numbers of human herpesviruses identified have grown three times since 1980; in 1986 HHV-6 was discovered ${ }^{1}$ and HHV-7 was isolated in $1990 .^{2}$ Eight years after the discovery of HHV-6 a variety of human illnesses such as roseola infantum, hepatitis, and mononucleosis syndrome was found to be caused or associated with HHV-6 infection..$^{3-5}$ HHV-7 is a $\beta$ herpesviruses as is cytomegalovirus (CMV) and HHV-6. Originally, HHV-7 was grown from the blood mononuclear cells of a healthy adult who was negative for human immunodeficiency virus (HIV). ${ }^{2}$ Among the human herpesviruses, HHV-7 is closest to HHV-6, with an estimated maximum sequence homology of 42 of $124 \mathrm{kB}^{6}$; they have both been discovered accidentally from activated peripheral blood mononuclear cells (PBMC) kept in long term culture with the help of interleukin 2; and they have similar cytopathic effects in cell culture. Therefore, HHV-7 is expected to induce a disease spectrum similar to that of HHV- $6 .{ }^{12}$ We present clinical and laboratory findings of two patients with mononucleosis syndrome associated with active HHV-7 infection.

\section{Case reports}

CASE 1

A 5 year old girl developed a cough, sore throat, and bilateral upper eyelid oedema. Fever and abdominal pain occurred four days later. Hepatosplenomegaly and leucocytosis with mononucleosis (white blood cell (WBC) count $16900 / \mathrm{mm}^{3}$; bands $6 \%$, segments $17 \%$, eosinophils $1 \%$, monocytes $3 \%$, lymphocytes $61 \%$, and atypical lymphocytes $12 \%$ ) were noted after admission. Serum aspartate aminotrans- ferase (AST) was $87 \mathrm{U} / 1$ and triglycerides $232 \mathrm{mg} / \mathrm{dl}$. The fever lasted for two days. Active HHV-6 or CMV infection was unlikely from serological studies done eight days after onset of symptoms: negative CMV IgM; CMV IgG antibody of $1: 16$; negative HHV-6 IgM antibody; and IgG HHV-6 antibody of 1:160. Active HHV-7 and Epstein-Barr virus (EBV) infections were indicated by the following results: IgG antibody against EBV early antigen (EA) of 1:160; positive IgM antibody against EBV viral capsid antigen (VCA); IgG antibody against EBV VCA of $1: 2560$; positive $\operatorname{IgM}$ antibody against $\mathrm{HHV}-7$; and negative IgG HHV-7 antibody. PBMC culture was positive for $\mathrm{HHV}-7$. Paired sera were obtained 15 days after disease onset; at that time EBV VCA IgG was 1:2560, HHV-7 IgM was positive, and HHV-7 IgG was 1:640. Antibody to EBV nuclear antigen (EBNA) was positive in both sera. There was still no evidence of active HHV-6 or CMV infection.

\section{CASE 2}

This 21 month old girl had an episode of fever that subsided the following day. Hepatosplenomegaly was found three days later and the WBC count one week later was 19590 cells $/ \mathrm{mm}^{3}$ with $70 \%$ atypical lymphocytes. Serum AST, alanine aminotransferase, and triglycerides were raised. Fever flared up eight days after the initial episode and lasted for three days. WBC count increased to $27000 /$ $\mathrm{mm}^{3}$ with $84 \%$ atypical lymphocytes. There was no evidence of active HHV-6 or CMV infection: serological studies included negative CMV IgM and IgG antibodies; negative HHV-6 IgM antibody; and IgG HHV-6 antibody of $1: 40$. Active HHV-7 and EBV infections were shown by the following results: IgG antibody against EBV (EA) of 1:10; positive IgM antibody against EBV VCA; IgG antibody against EBV VCA of 1:80; negative EBNA antibody; positive HHV-7 IgM antibody; and negative IgG HHV-7 antibody. PBMC culture was positive for HHV-7. Paired sera were obtained 24 days after disease onset; at that time, EBV VCA IgG was 1:40, HHV-7 IgM was positive, and HHV-7 IgG was 1:320. There was still no evidence of active HHV-6 or CMV infection.

\section{Discussion}

Although, clinically, HHV-7 has remained an orphan, this virus has been known to behave in many similar ways to HHV-6. The first disease linked to HHV-7 and HHV-6 was roseola infantum, ${ }^{37}$ soon after which both viruses were shown capable of inducing hepatitis, ${ }^{58}$ 
especially in infants. This report shows that, similar to HHV-6, HHV-7 is capable of inducing infectious mononucleosis-like illness. ${ }^{4}$

Both patients had simultaneous, active infections with HHV-7 and EBV. The seroconversion to $\mathrm{HHV}-7$ indicated a primary $\mathrm{HHV}-7$ infection in both cases. EBNA antibody is a useful serological marker that can distinguish between primary and reactivated EBV infection. ${ }^{9}$ In case 1 , positive EBNA antibody in the first serum showed that this patient had EBV reactivation. Case 2 appeared to have primary EBV infection because of the negative EBNA antibody. Therefore, HHV-7 is most likely to be responsible for the clinical manifestation of infectious mononucleosis-like illness of case 1 , but in case 2 it is difficult to determine the role played by each virus.

The finding of primary HHV-7 infection and reactivated EBV infection in case 1 suggests that $\mathrm{HHV}-7$ infection can induce EBV reactivation. This reasoning is supported by an in vitro model, which showed that members of human herpesviridae can augment the replication of each other. ${ }^{13}$ Our results showed that a patient can have simultaneous active infection of more than one herpesvirus; therefore, a complete panel of serological tests is necessary to determine the aetiological agent in herpesvirus related illnesses. Without the serological investigations into HHV-7, both of our patients might have been diagnosed with EBV induced infectious mononucleosis. These cases also raise the issue of in vivo interaction of herpesviruses. Infection with several herpesviruses may not be a rare event, and whether infection with more than one herpesvirus leads to more serious illness needs to be clarified.

An interesting finding in these two patients was hypertriglyceridemia, a biochemical indicator highly suggestive of prominent cytokine response. The most likely cytokine involved is tumour necrosis factor, which can decrease the activity of lipoprotein lipase and/or increase the hepatic synthesis of very low density lipoproteins. ${ }^{10-12}$ Whether this is a feature associated with $\mathrm{HHV}-7$ induced mononucleosis or is caused by dual infections (EBV and HHV-7 in these cases) remains to be answered.

We thank Mr Chuan-Liang Kao for help in completing the virological testing in this study.

1 Salahuddin SZ, Ablashi DV, Markham PD, et al. Isolation of a new virus, HBLV, in patients with lymphoproliferative disorders. Science 1986;234:596-601.

2 Frenkel N, Schirmer EC, Wyatt LS, Katsafanas G, Rffman E, Danovich RM, et al. Isolation of a new herpes virus from human CD4+ T cells. Proc Natl Acad Sci USA 1990;87: $748-52$.

3 Yamanishi K, Okuno T, Shiraki K, et al. Identification of human herpes virus-6 as a causal agent for exanthem subitem. Lancet 1988;i:1065-7.

4 Steeper TA, Horwitz CA, Ablashi DV, Salahuddin SZ, Saxinger C, Saltzman R, et al. The spectrum of clinical and laboratory findings resulting from human herpes virus-6 (HHV-6) in patients with mononucleosis-like illness not resulting from Epstein-Barr virus and cytomegalo virus. Am f Clin Pathol 1990;93:776-83.

5 Dubedat S, Kappagoda N. Hepatitis due to human herpes virus-6. Lancet 1989;332:1463-4.

6 Wyatt LS, Rodriguez WJ, Balachandran N, Frenkel N. Wyatt LS, Rodriguez WJ, Balachandran N, Frenkel N.
Human herpes virus 7: antigenic properties and prevalence Human herpes virus 7: antigenic properties a

7 Tanaka K, Kondo T, Torigoe S, Okada S, Mukai T, YamaniTanaka K, Kondo T, Torigoe S, Okada S, Mukai T, Yamani-
shi K. Human herpes virus 7; another causal agent for roseola (exanthem subitem). F Pediatr 1994;125:1-5.

8 Hashida T, Komura E, Yoshida M, et al. Hepatitis in association with human herpes virus-7 infection. Pediatrics 1995; 96:783-5.

9 Henle G, Henle W, Horwitz CA. Antibodies to Epstein-Barr virus associated nuclear antigen in infectious mononucleosis. F Infect Dis 1974;130:231-9.

10 DeForge LE, Nguyen DT, Kunkel SL, Remick DG. Regulation of the pathophysiology of tumour necrosis factor. $\mathcal{F}$ Lab Clin Med 1990;116:429-38.

11 Beutler B, Mahoney J, Le trang N, Pekala P, Cerami A. Purification of cachectic, a lipoprotein lipase-suppressing hormone secreted by endotoxin-induced RAW 264.7 cells. hormone secreted by endotoxin $1985 ; 161: 984-95$.

12 Kawakami M, Cerami A. Studies of endotoxin-induced decrease in lipoprotein lipase activity. $\mathcal{F}$ Exp Med 1981;154: 631-9.

13 Flamand L, Stefanescu I, Ablashi DV, Menezes J. Activation of the Epstein-Barr virus replicative cycle by human herpes virus 6. F Virol 1993;67:6768-77. 